\title{
Analysis of Political Language Based on Appraisal Theory: The Mutual Construction of Language and Power-Taking Xi Jinping and Donald Trump's Speeches at World Economic Forum as Examples
}

\author{
Zhang Siyou, Pei Zhongwen \\ Wuhan University of Science and Technology
}

\begin{abstract}
Davos Forum, also known as World Economic Forum, is a non-official international organization aiming at discussing problems in world economy and promoting international economic cooperation and communication. Based on James R. Martin's Appraisal Theory, this paper attempts to make a contrastive analysis between Xi Jinping's and Donald Trump's speeches at World Economic Forum in 2017 and 2018 respectively. The purpose is to explore how they convey ideology in their speeches, how they make use of language resources to coordinate emotions, judgments and appreciation, as well as how they engage and graduate semantic contents, thereby exploring the mutual construction of language and power.
\end{abstract}

Keywords-Appraisal theory; World Economic Forum; Attitude; Engagement; Graduation

\section{INTRODUCTION}

"Discourse analysis can't be restricted to the description of linguistic forms independent of the purposes or functions which those forms are designed to serve in human affairs." [1] Halliday pointed out that "language has three meta-lingual functions, namely, ideational, interpersonal and textual functions." [3] So while conducting discourse analysis, we should not only pay attention to language itself, but also information behind it. "As a kind of discourse, political discourse is regarded as the product of political system. It mainly involves a country's internal and external policies. The purpose is to create power through language to realize the political intention of politicians." [2] Lakoff pointed out that "politics is language and language is politics" [4]. Politicians' speeches at the annual World Economic Forum reflect the ideology of politicians and the country. Xi Jinping delivered a speech entitled " Jointly Shoulder Responsibility of Our Times, Promote Global Growth " at World Economic Forum in 2017, and proposed the concept of "a community of shared future for mankind". The speech was widely praised by the international community. This year, Donald Trump on World Economic Forum delivered a keynote speech focusing on "America First", passing us that its economy is strong, the trade deficit will be cut, and encourage business investment to return to America, which has aroused the concern of the international society. It can be seen that their positions and attitudes are quite different. Based on James R. Martin's Appraisal Theory, this paper attempts to make a contrastive analysis between Xi Jinping's and Donald Trump's speeches on World Economic Forum in 2017 and 2018 respectively. The purpose is to explore how they realize interpersonal function in their speeches, reveal how politicians make use of language resources to coordinate affect, judgment and appreciation, as well as how they engage and graduate semantic contents.

\section{APPRAISAL THEORY}

Appraisal Theory was put forward by Martin in the 1990s on the basis of interpersonal function and is a supplement to the "interpersonal function" in the systematic functional grammar of Halliday. Appraisal theory system is a set of resources for expressing attitudes through language, including three main systems: Attitude, Engagement and Graduation. "Attitude refers to the judgment and appreciation of human behavior, text or process, as well as phenomenon after the influence of psychology." [5] The center of the attitude system is the affect system, which serves as the basis for judgment and appreciation. "The judgement system evaluates the behavior of language users according to the standards of ethics and morality." "The appreciation system is the evaluation of text or process and phenomenon, including reaction, composition and valuation." [6] The engagement system is used to study the sources of attitude, mainly involving monogloss and heterogloss. White regards the expansion and contraction of dialogue as the important factors to divide heterogloss, supplemented by the investigation of sound source. "Heterogloss is divided into dialogic expansion and dialogic contraction." [7] The dialogic expansion is classified as entertain and attribute. "Dialogic contraction can be classified into proclaim and disclaim. Monogloss includes assertion and presumption. Graduation refers to the increase and decline of attitude, which can be graded. This is called "force". And as for those which can't be graduated, their degree can be increased or decreased by sharpening or blurring words, which is called "focus"." [8] Appraisal theory can be shown as follows: 


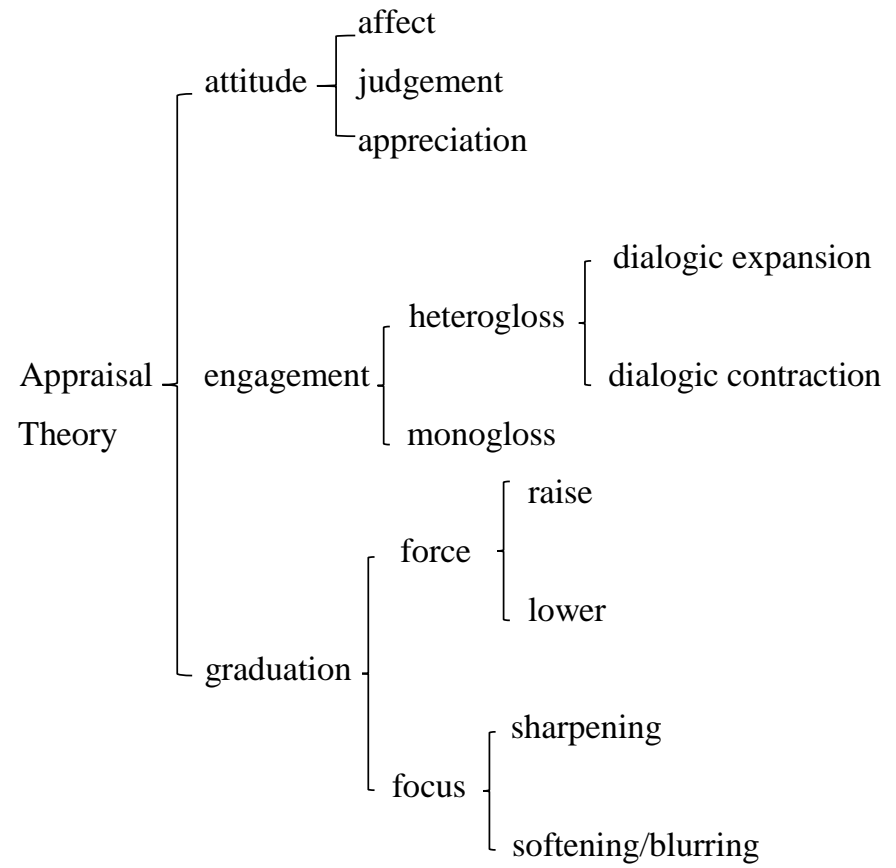

Fig. 1 Appraisal Theory

\section{CONTRASTIVE ANALYSIS OF XI JINPING AND DONALD TRUMP'S SPEECHES ON WORLD ECONOMIC FORUM}

\section{A. Attitude System}

Appraisal theory thinks that attitude refers to the psychological process of human behavior, text, or after the affected, and the phenomenon of judgment and appreciation, divided into affect, judgement and appreciation. This paper mainly analyzes the positive and negative attitude words in both speeches. After analysis of the two texts, the following conclusions are drawn: Donald Trump used a lot of positive words to describe what the United States has accomplished since he was elected, such as prosperity, extraordinary, great, confidence, strong, better, thrive, flourish etc. The purpose is to show he has done many things for American people, such as lowering the unemployment rate, reducing taxes in order to increase the national income, paying attention to the military construction to protect national security, reforming the immigration system and so on. At the same time, when talking about his achievements, he also used a lot of negative attitude words to form a contrast, such as poverty, violence, fear, stagnation, unemployment, burdensome etc. Therefore, by using both positive and negative attitude words, Trump has achieved the goal of affirming his own achievements and making his achievements more obvious through comparison. Overall, Trump used more positive words, because his speech was more about affirming the positive changes he has brought to America since he was elected, which is to show that the United States is in a very investment-friendly state and wants to attract more investment to develop American economy. Negative attitude words are used only to highlight the greatness of their achievements.
The use of positive and negative words in Xi Jinping's speech is also evident. At first, Xi Jinping pointed out that there are many problems in today's world and used many negative attitude words: frequent regional conflicts, terrorism, refugees, chaos etc. Use of a large number of negative attitude words can be seen that Xi Jinping is concerned about these issues, but he thinks it is caused by conflict and regional unrest. Secondly, he also used a lot of negative attitude words when pointing out the three major problems in today's world economy, such as lack of, difficult, slowest, ineffective, closed mechanisms etc. While when it later came to the solution, a large number of positive attitude words have been used, like dynamic, innovation-driven growth model, primary, well-coordinated etc. The use of such words indicates that Xi Jinping is concerned about the existing problems, but is positive about the proposed solutions. Finally, talking about China's achievements along the path of reform and opening up and the benefits of the "One Belt and One Road" policy, Xi Jinping, on the other hand, was generous with praise and used a lot of positive attitude words, but when it comes to the problems in China's development, there is no lack of negative attitude words.

\section{B. Engagement System}

The engagement system mainly studies the origin of attitude and considers that the language source of attitude is the subjective choice of monogloss or heterogloss. Under the guidance of engagement system, the paper found that the two leaders used more heterogloss than monogloss, and more contraction statements than expansion ones. The use of monogloss can be seen in the choice of person. The first person I is not frequently used in both texts, but "we", "you" and "people" are used more. This shows that both leaders avoid expressing only their personal views, but speak from the perspective of the nation and the whole mankind. In the use of heterogloss, dialogic contraction is more than dialogic expansion. The following are a few typical examples from $\mathrm{Xi}$ Jinping's speech:

Example 1: "This is indeed heartbreaking."

Example 2: "It has proved to be a right strategic choice."

Example 3: "World history shows that the road of human civilization..."

Example 4: "However, the global governance system has not embraced..."

Example 5: "China will keep its door wide open and not close it."

"Indeed" belongs to "pronounce" according to Martin's appraisal theory. It represents a strong tone, giving the audience no room for consultation. "Prove" and "show" belong to "endorse". "However," belongs to "concede" in "concur". "Not" belongs to "deny" in "disclaim".

Similarly, Donald Trump made good use of dialogic contraction. The most obvious is the use of "deny" in "disclaim". The following are a few typical examples:

Example 1: “But America first does not mean America alone." 
Example 2: "We cannot have free and open trade if some countries exploit the system at the expense of others."

Example 3: "That's what we're doing in America, and the results are totally unmistakable."

Example 4: “The United States will no longer turn a blind eye to unfair economic practices ..."

Example 5: "As the United States pursues domestic reforms to unleash jobs and growth..."

The above examples represent the negative means in Trump's speech, which can be classified into two kinds. The first one is the direct use of "not" or "no", and the second way is to use the negative prefix. Either way of negation reduces the space for dialogue and makes its position and attitude very clear.

\section{Graduation System}

Graduation refers to the increase or decrease in attitude, and its degree can be classified. For a person or thing that can be classified, we describe it through force, which is done by enhancing adverbs and Numbers. For a person or thing that cannot be classified, we describe it through focus. By using graduation system to analyze the two texts, this paper finds that the speeches of the two leaders on World Economic Forum use a lot of means to show the force and focus.

First of all, the strength and weakness of force are reflected in the application of a large number of data, mainly when both sides talk about their achievements. Xi Jinping used a large number of specific figures to illustrate the benefits of China's reform and opening up policy, confirming the correctness of this road. Trump described the welfare of the tax cuts bringing to people of the United States. The use of a large number of detailed numerical makes force stronger, presentation of things more convincing, achievements more obvious.

Secondly, the strength and weakness of force are reflected in the use of a large number of comparative levels and superlatives. The following are some typical examples:

Example 1: "The growth of the global economy is now at its slowest pace in seven years."

Example 2: “The richest one percent of the world's population own more wealth than the remaining 99 percent."

Example 3: "This is the biggest challenge facing the world today."

Example 4: "All these figures are among the highest in the world."

Example 5: "We have succeeded beyond our highest expectations."

It can be seen from the above examples that a large number of comparative and superlative uses make force stronger. We can see both the confidence and expectation of the future of the two countries and the concerns of the issue, which can better attract the attention of the audience.
Finally, for people or things that cannot be classified, the two leaders adopted sharpening and blurring means, mainly some adverbs of degree. The following are some typical examples:

Example 1: "It is the consequence of excessive chase of profit by financial capital and grave failure of financial regulation."

Example 2: "The global economy has remained sluggish for quite some time."

Example 3: "The global economic landscape has changed profoundly in the past few decades."

Example 4: " Countries have extensive converging interests and are mutually dependent."

Example 5: "We have dramatically cut taxes which make America competitive."

From the above examples, we can see that the leaders of the two countries are more inclined to use sharpening words to express their attitudes and views. Such speeches are more likely to attract the attention of the audience, because the audience can clearly judge the speaker's attitude towards things.

\section{CONCLUSIONS}

This paper finds out in the research that positive words in both speeches related to attitude are more than negative words. They tend to express their joy, pride and confidence, adopt positive attitude to express their firm beliefs and views, give the audience confidence and expectation, and inspire their morale and determination to face future challenges and difficulties. However, for problems in the world today, such as nuclear weapons, terrorism, refugee and other issues, the two leaders are negative, criticized its negative influence, but is optimistic for the solution of these problems. Under the guidance of engagement system, the paper found that both leaders used heterogloss than monogloss, dialogical contraction than dialogic expansion, with the purpose of expressing the determination of two countries to face difficulties and their ability to solve them. Based on graduation system, both leaders used strength or weakness of force and sharpening or blurring of focus to show different levels of evaluation meaning. The extensive use of data shows the achievements and goals of both countries and reflects the objectivity and concreteness of their speeches. But the purpose of using appraisal theory to organize speeches is different. Xi Jinping's speech was more from the perspective of mankind as a whole, calling on all countries in the world to unite to shoulder their responsibilities and emerge from economic difficulties. He focused on globalization, which is targeted at global protectionism and populism. Donald Trump, on the other hand, spoke for the United States, first promoting the achievements since he was elected, then calling on countries to cooperate with the United States and invest in the United States, which can be seen as a speech of advertising for the United States. The substance and purpose of his speech was to promote the concept of "American first" and unilateral trade. 
Therefore, as speakers, they are easier to make their speeches more persuasive and effective if the speeches are written under the guidance of appraisal theory; as listeners, they are easier to see the ideology hidden behind. So, language and power are mutually constructed and influenced. Through analyzing and evaluating the distribution and application of resources in the speeches of both leaders, this paper hopes to provide a reference for the better writing and understanding of such speeches and hope to develop a wider range of application of appraisal theory.

\section{REFERENCES}

[1] Brown, G. \&Yule, G. Discourse Analysis [M]. Cambridge: Cambridge University Press, 1983.

[2] Fowler, R. Language and Control [M]. London: Routledge \& Kegan Paul. 1979.

[3] Halliday, M. A. K. An Introduction to Functional Grammar [M]. with the third edition revised by C. M. I. M. Matthiessen. London: Arnold, 2004.

[4] Lakoff. R. Talking Power: the Politics of Language in Our Lives. [M]. USA: Basic Books, 1990.

[5] Martin \& White. The Language of Evaluation - Appraisal in English [M]. London / New York: Palgrave Macmillan, in press, 2005.

[6] Martin, J. R. \& David Rose. Working with Discourse: Meaning Beyond the Clause [M]. Continuum, Peking University Press, 2003/2007.

[7] Martin, J. R. Beyond exchange: APPRAISAL Systems in English [ J]. In S. Hunston and G. Thompson (eds.). Evaluation in Text: Authorial Stance and the Construction of Discourse [C]. Oxford: OUP, 2000: $142-175$. 